\title{
LA INFLUENCIA DEL DERECHO DE DAÑOS EN LA RESPONSABILIDAD DEL ESTADO POR FALTA DE SERVICIO
}

\section{THE INFLUENCE OF TORT LAW ON STATE LIABILITY FOR LACK OF SERVICE}

Gustavo Poblete Espíndola*

\section{RESUMEN}

El presente artículo analiza la influencia del derecho de daños en la responsabilidad del Estado por falta de servicio desde la teoría de Peter Cane desarrollada en Tort Law and Public Functions. En este punto, la investigación analiza tres aspectos fundamentales: la estructura normativa en las relaciones de desigualdad jurídica, el rol del ideal igualitario en la responsabilidad estatal y el deber de indemnizar los daños causados por los agentes públicos. Primero, establece que la estructura normativa de la responsabilidad pública debe ser entendida en términos de justicia correctiva, puesto que existe una parte que debe corregir el daño ilegítimo causado por otra. Segundo, sostiene que la igualdad entre las partes funciona como criterio distributivo para contrarrestar la subordinación estatal ejercida sobre el administrado. Por último, contrasta los objetivos de la responsabilidad estatal y del derecho daños e identifica las razones generales por las cuales la Administración debería indemnizar los daños causados a los administrados.

* Abogado. Licenciado en Ciencias Jurídicas y Sociales por la Universidad Alberto Hurtado, Chile. Doctor en derecho por la Universidad de Chile (Chile) y la Universitat de Girona (España). Profesor e investigador del departamento de derecho público, Universidad Alberto Hurtado. Dirección postal: Cienfuegos 41, Santiago. Correo electrónico: gpoblete@uahurtado.cl

El artículo forma parte del Proyecto "Hacia una consolidación de la Teoría de los Ilícitos Estatales en las actuaciones de la Administración Penitenciaria”, en el marco de los Fondos Internos de Fomento a la Investigación 2019-2020 de la Facultad de Derecho de la Universidad Alberto Hurtado, del cual el autor es investigador responsable. El autor agradece las observaciones de una versión preliminar a Raúl Letelier, Diego Papayannis, José Miguel Valdivia, Enrique Barros, Felipe Oyarzún, Carolina Meza, Claudio Agüero y Bárbara Chávez. También, los comentarios realizados por el arbitraje anónimo, los cuales ayudaron a mejorar el producto final de esta investigación.

Recepción: 2020-12-16; aceptación: 2021-04-19. 
Palabras Clave: responsabilidad del Estado; derecho de daños; filosofía del derecho administrativo; desigualdad jurídica; compensación monetaria

\section{AbStRACT}

This article analyzes the influence of tort law on State liability for lack of service from Peter Cane's theory developed in Tort Law and Public Functions. At this point, the paper addresses three fundamental aspects: the normative structure in the relationships of juridical inequality, the role of egalitarianism in State responsibility, and the duty to compensate the damages caused by public agents. First, it states that the normative structure of public responsibility must be understood in terms of corrective justice since there is a party that must correct the illegitimate damage caused by another. Second, it proposes that equality between the parties functions as a distributive criterion to reduce the state subordination exercised on the administered. Finally, it contrasts the objectives of State responsibility and tort law and identifies the general reasons why the Administration should compensate for the damages caused to the administered.

46 KeYwORDs: state liability; tort law; philosophy of administrative law; juridical inequality; monetary compensation

\section{INTRODUCCIÓN}

Desde D. con Fisco de $C_{h i l e}{ }^{1}$, se encuentra instalado en la dogmática administrativista el debate sobre el lugar que ocupan las reglas y principios del derecho civil en la responsabilidad extracontractual del Estado. Esta discusión se particulariza cuando en S. con Fisco de Chile ${ }^{2}$ se aplica el artículo 2314 del Código Civil ante la ausencia de una norma expresa que impute responsabilidad por falta de servicio a las Fuerzas Armadas ${ }^{3}$. El ejercicio argumentativo realizado por el tribunal comprendió el traslado de los elementos que conforman la noción de culpa civil hacia la falta de servicio, de tal forma que se completa el cuadro regulativo con el derecho común.

El diálogo entre el derecho administrativo y el derecho civil en esta materia es atribuido a Pierry, quien redactó S. con Fisco de Chile fortale-

${ }^{1}$ M. D. con Fisco de Chile (2002), considerando décimo.

${ }^{2}$ Una visión crítica sobre los argumentos de la Corte Suprema, véase en Román (2009), pp. 310-317.

${ }^{3}$ P. S. con Fisco de Chile (2009), considerando décimo sexto. 
ciendo el lugar de la falta de servicio como el título de imputación ${ }^{4}$. A partir de dicha interpretación, la discusión sobre la naturaleza jurídica de la responsabilidad extracontractual del Estado fue relegada a un segundo plano, y se dio paso a la discusión sobre los alcances de la responsabilidad del Estado por falta de servicio ${ }^{5}$. En este nuevo escenario, la dogmática administrativista ha intentado dar fisonomía al régimen de responsabilidad estatal desde la faute de service desarrollada por la jurisprudencia francesa ${ }^{6}$, enfocando su análisis en los distintos sectores regulados ${ }^{7}$. No cabe duda de que los esfuerzos desplegados han sido útiles para vincular ambas parcelas del derecho. Sin embargo, persisten algunas preguntas sobre los fundamentos que justifican la aplicación específica del derecho de daños en la responsabilidad extracontractual del Estado.

El presente artículo se sitúa en este vacío normativo de la legislación chilena e intenta determinar la influencia del derecho de daños en la conformación y comprensión de la responsabilidad del Estado por falta de servicio. Para realizar este análisis, la investigación se posiciona en la teoría formulada por Peter Cane en Tort Law and Public Functions, que, para efectos de este trabajo, se denominará "teoría de los ilícitos estatales". Este enfoque metodológico, permite dar una explicación teórica sobre la estructura y el funcionamiento de la responsabilidad pública en el common law y modelar dicha formulación al régimen de responsabilidad estatal nacional. De esta forma, los argumentos desplegados provienen desde lo que podría denominarse filosofía del derecho administrativo, pues buscan depurar los conceptos implícitos y el discurso científico del derecho administrativo en esta materia ${ }^{8}$.

La postura que defiende Cane sostiene que el marco teórico utilizado por el derecho de daños en las relaciones entre privados puede ser aplicado, con algunas variantes, a las relaciones entre el Estado y los particulares ${ }^{9}$. La investigación trabaja sobre esta hipótesis y desarrolla tres argumentos

${ }^{4}$ Las ideas que sientan la postura jurisprudencial de Pierry se pueden encontrar en Pierry (2004), pp. 11-19. El factor Pierry es decisivo para la consagración jurisprudencial de la falta de servicio como título de imputación subjetiva. Véase CORDERo (2018), pp. 78-80.

${ }^{5}$ Para Letelier es bastante claro que la discusión sobre la responsabilidad del Estado debe centrarse en el análisis sectorizado de la falta de servicio. Véase Letelier (2012), pp. 1-26.

${ }^{6}$ Sobre los orígenes de la falta de servicio, véase VALDivia (2012), pp. 29-43.

${ }^{7}$ Por ejemplo, véase Agüero et al. (2020), pp. 171-191; Poblete (2015), pp. 243-251; VALDivia (2020), pp. 213-246; y, los trabajos de la sección La falta de servicio en contexto en LETELIER (2012), pp. 133-321.

${ }^{8} \mathrm{Si}$ bien no existe una obra que establezca las coordenadas exactas de la filosofía del derecho administrativo, bien vale destacar los esfuerzos realizados desde el common law por Cane (2011); Harlow (2004); Endicott (2018); y, Cornford (2008).

${ }^{9}$ Véase Cane (2014), p. 150. 
que corrigen, complejizan y consolidan la TIE como una teoría que sirve para comprender el régimen de responsabilidad estatal chileno basado en la falta de servicio.

Este trabajo presenta el siguiente orden. Primero, delimita el objeto de estudio y revela la necesidad de articular una explicación exhaustiva para justificar la presencia del derecho de daños en la responsabilidad del Estado por falta de servicio. Segundo, expone los elementos centrales de la TIE sobre los cuales se posiciona la investigación y que serán objeto de un análisis profundo: estructura relacional, componentes y propósitos. Tercero, determina la estructura normativa de las interacciones públicas, centrando la atención en la correlatividad de las partes involucradas en la interacción pública. Cuarto, dilucida el componente generador de equilibrio entre partes jurídicamente desiguales, mediante el análisis del principio de igualdad como criterio distributivo en relaciones jurídicas que manifiestan una asimetría de posiciones. Quinto, desde una explicación plural, asimila los objetivos del derecho administrativo y del derecho de daños como herramientas funcionales para explicar el carácter compensatorio de la responsabilidad por rendición de cuentas (accountability). Por último, entrega algunas conclusiones preliminares que reflejarán la incidencia del derecho de daños en la responsabilidad del Estado por falta de servicio.

Antes de comenzar se realizará una prevención metodológica. Esta investigación pretende rearticular una posición teórica que sea útil para la depuración del discurso científico del derecho administrativo. El camino trazado pretende seguir la empresa explicativa de la filosofía del derecho administrativo. Por esa razón, los argumentos que se confeccionan se encuentran sustentados en ideas desarrolladas por otras áreas consolidadas, tales como la filosofía del derecho privado, la filosofía política y la teoría analítica del derecho. En atención a lo antes señalado, se despeja la realización de un estudio de derecho comparado, aunque para facilitar la lectura del argumento principal, en algunos pasajes del trabajo, se fijan similitudes o diferencias explícitas entre el common law y el civil law.

\section{LA AUSENCIA DE UNA EXPLICACIÓN EXHAUSTIVA:}

EL PUNTO DE PARTIDA

En la introducción se anticipó el diagnóstico general del presente trabajo: los administrativistas chilenos, en un ejercicio constante y uniformado, han intentado darle forma a la falta de servicio utilizando las reglas y principios del derecho de daños. Toda esta tendencia se consolida cuando la jurisprudencia asimila la falta de servicio a la culpa civil para responsabilizar 
a las Fuerzas Armadas mediante una interpretación extensiva del artículo 2314 del Código Civil. Esto produce que los tribunales decidan casos de derecho público elaborando argumentos que incorporan instituciones del derecho civil. Se trata de un ejercicio interpretativo que exige distinguir las diferencias y semejanzas en dichos ámbitos, para obtener un producto que sea útil en el juicio de responsabilidad.

Según Barros, la responsabilidad civil se ordena sobre el principio de igualdad, donde ninguna de las partes tiene la potestad de ejercer control sobre otra. Por el contrario, en el derecho público es característico que las autoridades tengan la potestad de interferir en los intereses de los particulares para satisfacer el interés público ${ }^{10}$. En estos términos, la distancia entre un ámbito y otro es la potestad que tiene la Administración sobre el administrado versus la relación horizontal que prima entre los privados. Mientras que en el ámbito público la intervención de intereses particulares es legítimo, en el ámbito privado cualquier menoscabo en los intereses legítimos de los participantes de la interacción constituye un daño.

En cuanto a las analogías, bien vale recalcar el tardío reconocimiento de la responsabilidad del Estado respecto de la responsabilidad civil. Ello explica que el derecho de daños sea una fuente indispensable para la construcción del sistema de responsabilidad público chileno, ya que, con algunos ajustes, ha permitido la conformación de una doctrina administrativista capaz de dar cuenta de los daños provocados por las funciones que desempeñan las reparticiones públicas. Como expresa Barros,

"el complejo ordenamiento de la responsabilidad extracontractual actúa como estatuto general y supletorio en las materias que no son objeto de conceptos y reglas especiales de derecho público"11.

Si bien los participantes de la relación son diferentes, la manera de enfrentar las demandas por indemnización de perjuicio tiene una raíz común. El sistema de responsabilidad público encuentra una base conceptual que no tan sólo es útil para atribuir responsabilidad sobre la base de reglas generales, sino que también en sectores donde la falta de servicio está contenida en leyes especiales, con reglas de atribución de responsabilidad propia.

Los conceptos de daño, culpa y causalidad vienen a demostrar que las interacciones públicas no se alejan jurídicamente de las dinámicas del derecho privado. Tampoco difieren en su autonomía conceptual. Esto quiere decir que la existencia de un presupuesto no determina la concurrencia de otros. Por ejemplo, es posible que una persona sufra un daño ilegítimo,

${ }^{10}$ Véase Barros (2020), p. 505.

${ }^{11}$ Barros (2020), p. 506. Cursivas en original. 
sin que sea posible establecer la negligencia de la actuación o identificar al causante. Las líneas que siguen buscan mostrar sucintamente la convergencia del daño, culpa y causalidad en el ámbito privado y público.

El daño cometido por el Estado, según las reglas de la responsabilidad civil, debe ser resarcido en su integridad ${ }^{12}$. Esto quiere decir que tanto los daños sufridos en el patrimonio, como los daños morales deben ser compensados cuando se logra demostrar la falta de servicio de la repartición pública. Para Ferrada,

"la obligación reparatoria del Estado recae, en primer lugar, sobre los daños materiales o patrimoniales, que son aquellos que afectan bienes que tienen un significado económico que expresa un valor de cambio, lo que se traduce en una disminución del activo (daño emergente) o en la imposibilidad de su incremento (lucro cesante)"13.

En este plano, se sitúan algunos ejemplos que develan este tipo de menoscabo injustificado, como en los servicios de salud cuando después de una operación queda una aguja dentro del cuerpo del paciente causando un daño en su integridad física, o cuando por motivo de una acera que presenta desperfectos una persona sufre una caída y se lesiona una de sus extremidades.

La indemnización de perjuicios también comprende aquellos daños sufridos fuera del patrimonio de la víctima. El resarcimiento del daño moral viene a dar completitud a la obligación que tiene el Estado. Sin perjuicio de ello, y a diferencia del derecho civil, su conceptualización se ha ido ampliando y ha encontrado mayores planos de certeza para el pago de indemnizaciones. Según el artículo 41 de la ley n. ${ }^{\circ}$ 19966, que regula las garantías en salud, el daño moral se determina en virtud de la gravedad del perjuicio y la modificación de las condiciones de existencia del afectado, en atención a su edad y condición física ${ }^{14}$. Aquello se ve fortalecido vía reglamentaria cuando se establecen montos máximos a pagar según el daño sufrido por la víctima ${ }^{15}$. En estos términos, la fijación de montos

${ }^{12}$ Véase Barros (2020), p. 526. Para Barros, siguiendo el razonamiento de Chapus en Francia, no existen normas especiales ni razones jurídicas suficientes para hacer distinciones sustantivas entre la reparación civil y la administrativa.

${ }^{13}$ Ferrada (2020), p. 399.

${ }^{14} \mathrm{El}$ artículo 41 de la ley n. ${ }^{\circ} 19966$ señala que: "La indemnización por el daño moral será fijada por el juez considerando la gravedad del daño y la modificación de las condiciones de existencia del afectado con el daño producido, atendiendo su edad y condiciones físicas".

${ }^{15}$ Con ello se hace referencia a la resolución n. ${ }^{\circ} 142$ exenta, que fija los montos máximos a pagar por los prestadores institucionales públicos en virtud del procedimiento de mediación establecido por la ley n. ${ }^{\circ} 19966$. 
aproximados es considerada como un criterio de razonabilidad para determinar los parámetros aceptables de una indemnización, constituyendo un límite a las indemnizaciones excesivamente onerosas en contra del Estado $^{16}$. Por esa razón, el resarcimiento cumple una función reparatoria cuando, por ejemplo, la madre sufre la pérdida de su hijo en gestación debido a la atención médica negligente prestada por el hospital público.

Por su parte, la vinculación entre la culpa civil y la falta de servicio se encuentra establecida en razón de la regla de responsabilidad del artículo 2314 del Código Civil. Como se indicó antes, esta regla establece que una persona es obligada a indemnizar cuando haya inferido daño a otra. En el derecho administrativo, esta regla se traduce en que el Estado es responsable de los daños causados por falta de servicio. La aplicación en uno y otro ámbito responde a un patrón común: el causante de un perjuicio injustificado debe responder mediante su indemnización. No obstante, surgen algunos matices sobre el estatus jurídico del causante del daño que es menester precisar para completar la explicación.

Si bien la dogmática y la jurisprudencia administrativista chilena durante estos últimos años han asimilado la culpa civil y la falta de servicio, no es lo mismo determinar la negligencia de un particular y la falta de servicio de un órgano estatal. Los niveles de intervención son diferentes por el mandato jurídico que rige en uno y otro caso. Por un lado, la culpa en la responsabilidad extracontractual está determinada por aquellas actuaciones que no alcanzan el umbral del cuidado razonable, es decir, aquellas conductas que no respetan o transgreden ciertos estándares de diligencia dispuestos por el derecho civil ${ }^{17}$. Por otro lado, la falta de servicio está fijada por una obligación legal y el cumplimiento del interés público. La negligencia se produce cuando el servicio público no cumple con el deber legal impuesto y/o cuando se ejecutan conductas contrarias a la finalidad perseguida. En el primero, lo relevante es que no se modifique de manera indebida la relación de igualdad de las partes en la interacción. En tanto, en el segundo lo relevante es que la desigualdad originada legítimamente en la ley no se agudice producto de las potestades y obligaciones impuestas a la Administración.

Por último, en ambos planos el nexo causal se conjuga de una manera similar: el daño sufrido por la víctima debe haber sido producido por una actuación negligente del demandado. Según esta comprensión, en el derecho civil la causalidad estaría dada en razón de la vinculación entre la

${ }^{16}$ Véase Ferrada (2020), p. 400.

${ }^{17}$ Con esto se hace referencia a que la diligencia debida depende del cumplimiento de estándares de diligencia generales y particulares. Un análisis detallado sobre estándares de diligencia civil y razonabilidad, véase en PAPAYAnNis (2020), pp. 9-38. 
culpa del demandado y el daño sufrido por el demandante. Lo relevante en todo esto es resolver la pregunta sobre cómo ocurrieron los hechos y si ellos poseen una conexión fáctica. Siguiendo a Papayannis, podría decirse que incluso en un caso sencillo nos preguntamos no tan sólo si la acción del agente fue, en las circunstancias que tuvo lugar, condición necesaria para la producción del daño, sino que también sería necesario resolver la conexión entre la acción u omisión del demandado y su resultado en la víctima ${ }^{18}$.

En el derecho público lo importante es constatar la relación entre la falta de servicio del órgano de la Administración y el daño sufrido por el administrado. Sobre este punto, Barros sostiene que la causalidad está determinada por el análisis de la falta de servicio desde la finalidad que la norma impone a cada repartición pública, y si esa finalidad está destinada a evitar el daño producido al administrado ${ }^{19}$. En estos términos, si una norma cualquiera impone a un servicio público la obligación de prestar un conjunto de atenciones sanitarias para resguardar la salud de la población, entonces cualquier conducta dañosa que se aleje de dicha obligación podría ser atribuible a la Administración. En este ámbito, el análisis del nexo causal requiere de la constatación entre una actuación administrativa negligente, en razón de que no persigue la finalidad legal impuesta, y un daño ilegítimo que la víctima no tiene la obligación jurídica de soportar.

Ubicadas las diferencias y similitudes entre ambos sistemas de responsabilidad, queda preguntarse si ello es suficiente para reducir los problemas de aplicación que presenta la responsabilidad del Estado por falta de servicio. En principio pareciera ser que no. Hasta ahora, los esfuerzos de los administrativistas se han centrado en trabajar sobre las similitudes y diferencias entre la responsabilidad civil extracontractual y la responsabilidad del Estado por falta de servicio. Sin embargo, este trasplante de reglas y principios reclama colmar un vacío: hacen falta razones que justifiquen la aplicación del derecho de daños en las hipótesis de responsabilidad por falta de servicio. Se encuentra patente la ausencia de una explicación exhaustiva que permita dilucidar las razones para usar conceptos y categorías desde el derecho de daños a la responsabilidad estatal. Precisamente, este es el punto de partida de la presente investigación.

\section{La TIE en el Pensamiento de Peter Cane}

La formulación teórica que desarrolla Cane intenta justificar la utilización de reglas y principios provenientes del derecho de daños en la responsa-

\footnotetext{
${ }^{18}$ Véase Papayannis (2014), pp. 77-78.

${ }^{19}$ Véase Barros (2020), p. 527.
} 
bilidad pública. Como se dijo antes, el argumento que sostiene el autor señala que para explicar el funcionamiento del derecho de daños entre los agentes privados y los agentes públicos se necesita un marco teórico diferente de aquel usado para explicar la aplicación del derecho de daños en las relaciones de igualdad jurídica. Para lograr aquello, analiza la estructura normativa, las características y los objetivos de las relaciones de desigualdad jurídica que se originan en las hipótesis de responsabilidad del Estado.

\section{Estructura normativa}

Para Cane, las RDJ tienen un origen funcional. En palabras sencillas, esto quiere decir que las funciones públicas desempeñadas, ya sea por un organismo gubernamental o no, van a determinar la interacción en este ámbito. La justificación de este argumento radica en lo que Cane entiende por función pública, esto es, aquella se realiza en beneficio de los intereses públicos, en lugar de satisfacer los propios del funcionario o de cualquier individuo o grupo de personas dentro de la sociedad ${ }^{20}$. Por lo tanto, el autor se aparta de la clásica separación normativa que existe entre funcionarios o agentes públicos, que actúan en nombre del Gobierno, y agentes privados, que buscan satisfacer el interés propio.

Esta manera alternativa de mirar las relaciones entre Estado y ciudadanos permite incorporar a los organismos no gubernamentales que ejercen funciones públicas, $y$, a su vez, descartar a los organismos gubernamentales que ejercen funciones privadas. La razón para sostener que los organismos no gubernamentales son parte de una RDJ es porque pueden ejercer funciones públicas sin la necesidad de anteponer la fuerza estatal sobre los ciudadanos, mientras que los organismos gubernamentales dejan de ser parte de una $\mathrm{RDJ}$ porque pueden desempeñarse en un ámbito privado. En este último supuesto, el autor incorpora dos ejemplos: la suscripción de contratos y la función privada que ejerce un conductor que maneja desde un lugar a otro ${ }^{21}$.

En resumen, el objetivo de Cane es mostrar que la estructura normativa de las RDJ está compuesta por entidades gubernamentales y no gubernamentales que desempeñan funciones públicas mediante agentes públicos, y entidades privadas que persiguen sus propios proyectos mediante agentes privados ${ }^{22}$.

${ }^{20}$ Véase CANe (2014), p. 151.

${ }^{21}$ En este cabe destacar la acotación que realiza Cane, cuando indica que en el common law no existe una distinción tajante entre el poder de contratación de los privados y el poder de contratación ejercido por las entidades estatales. Véase CANE (2014), p. 152.

${ }^{22}$ Véase CANe (2014), p. 153. 


\section{Componentes}

Uno de los aspectos que atrae la atención de los administrativistas es que desde las teorías no instrumentalistas no se descarta la aplicación del derecho de daños en las RDJ. Weinrib ${ }^{23}$, Steven ${ }^{24}$ y Beever ${ }^{25}$ piensan que el derecho de daños se entiende de mejor manera desde sus características jurídicos en lugar de sus funciones u objetivos. Esta perspectiva permite que exista un acuerdo, más bien implícito, para analizar la igualdad como un componente que genera equilibrios en las RDJ.

A partir de los flancos desarrollados por los teóricos no instrumentalistas, Cane comienza a demarcar el campo del derecho de daños y a teorizar sobre las RDJ. Así, Cane se pregunta por el modelo de justicia que debería utilizarse para comprender correctamente el régimen de responsabilidad civil extracontractual. Inicialmente, expone la postura de Weinrib que supone una posición totalmente apegada a un modelo de justicia correctiva, donde la noción de correlatividad expresa el derecho que posee una de las partes versus el deber que tiene la otra. Cane entiende que Weinrib adhiere a un internalismo que desestima las consideraciones distributivas, puesto que requieren de una elección política que afecta los intereses de los miembros de una comunidad, cuestión que no es propia de las relaciones entre privados ${ }^{26}$. La férrea defensa que hace Weinrib por dar fisonomía propia al derecho privado desde una plataforma propia, sin recurrir a fundamentos externos, hace que toda cuestión distributiva quede fuera de su análisis formal ${ }^{27}$.

Por el contrario, Cane identifica en las posturas de Wilberg y du Bois una apertura a las consideraciones distributivas en las relaciones de igualdad que se originan en el ámbito privado y, cuya consecuencia, lleva a contemplarlas en las RDJ. En ambas posiciones, destaca que los autores compatibilizan la incorporación de aspectos correctivos y distributivos tanto en la responsabilidad civil como en la responsabilidad estatal, aunque existe una diferencia en el camino adoptado para lograr dicho resultado. Wilberg estipula la posibilidad de incorporar en el terreno del derecho de daños las obligaciones estatales mediante la producción de normas ${ }^{28}$, mientras que la perspectiva de du Bois no sostiene problemas para que

${ }^{23}$ Véase Weinrib (2017).

${ }^{24}$ Véase Stevens (2007).

${ }^{25}$ Véase Beever (2007).

${ }^{26}$ Véase CANe (2014), p. 155.

${ }^{27}$ Cabe recordar que la tesis que defiende Weinrib es que "el derecho privado solo puede ser captado desde dentro y no como la manifestación jurídica de un conjunto de objetivos extrínsecos”. WeINRIB (2017), p. 39.

${ }^{28}$ Véase CANE (2014), p. 156. 
los tribunales decidan las controversias en términos distributivos, es decir, que resuelvan casos teniendo en cuenta el interés público que debe perseguir un funcionario ${ }^{29}$.

Sobre esta base, Cane comienza a teorizar y propone una fórmula para integrar las RDJ en el derecho de daños. Este planteamiento confecciona un componente generador de equilibrio entre partes jurídicamente desiguales, a partir de la asimilación del principio de igualdad y el principio de proporcionalidad. Esta teoría, estima que en términos formales o estructurales la sociedad se organiza en relaciones bilaterales entre agentes jurídicamente iguales y, en términos sustanciales, refleja una igualdad entre agentes al lograr un equilibrio en la libertad de cada uno para perseguir sus propios proyectos y propósitos. En atención a la demarcación del derecho de daños, Cane se suma a la idea de que el derecho de daños se puede aplicar a las relaciones de desigualdad jurídica con la misma estructura bilateral y correlativa que cuando se aplica a las relaciones de igualdad jurídica. Por lo tanto, es posible aplicarlo en las relaciones que se producen entre agentes públicos y privados, tanto en la estructura como en la sustancia ${ }^{30}$.

En este punto, Cane intenta dar una respuesta recurriendo al análisis que hacen Weinrib y Weinrib sobre el impacto horizontal de los derechos humanos en el derecho de daños ${ }^{31}$. En su análisis, ellos distinguen el rol que cumplen los derechos humanos en la regulación jurídica de las relaciones de desigualdad (entre ciudadanos y gobierno) y en las relaciones de igualdad (en el derecho privado). En estos dos casos, el componente diferenciador es la proporcionalidad, pues mientras que en el primero (aplicación directa) expresa un equilibro entre el derecho protegido y el interés público, en el segundo (aplicación indirecta) entrega un equilibrio de intereses entre dos iguales jurídicos.

El último caso le interesa a Cane, puesto que en principio existe una posición simétrica entre ambas partes que buscan satisfacer sus propios intereses o proyectos. Sin embargo, cuando el interés protegido es un derecho humano la balanza se inclina por aquel agente que alega su protección (por ejemplo, el derecho a vivir en un medio ambiente libre de contaminación), respecto de quien reclama tutela de un interés que podría considerarse marginal (por ejemplo, el deseo de prender fuego para cocinar una carne asada). El elemento que genera la desigualdad entre las partes en disputa es el derecho humano invocado por una de ellas, ya que

${ }^{29}$ Véase CANe (2014), p. 157.

${ }^{30}$ Véase Cane (2014), p. 161.

${ }^{31}$ Véase CANE (2014), p. 161 argumenta su posición citando a WeInRIb y WeinRib (2001), p. 58. 
"la presencia de un valor constitucional da mayor peso al interés de una parte que el que tendría en su ausencia, podríamos decir plausiblemente que el valor constitucional introduce un elemento de inequidad en la relación entre las partes"32.

Desde esta perspectiva, una relación de igualdad entre dos agentes particulares puede transformarse en una RDJ en el ámbito privado. Para Cane este análisis es clave, porque se entrelaza el principio de igualdad del derecho de daños con la versión del principio de proporcionalidad del derecho privado de Weinrib y Weinrib, lo que fortalece la capacidad del derecho de daños para entregar soluciones a las RDJ que se originan tanto en un ámbito privado como en un ámbito público ${ }^{33}$. De esta forma, si el derecho de daños es capaz de equilibrar los intereses de una RDJ originada entre privados, también lo podría hacer en una RDJ surgida entre el Estado y los ciudadanos.

\section{Propósitos}

El último aspecto que Cane analiza se relaciona con la aproximación instrumental adoptada en la TIE. En la identificación de problemas, observa la dificultad de trasladar las instituciones de compensación privada al ámbito de la Administración. En particular, destaca que la responsabilidad civil extracontractual posea diferentes herramientas para promover sus fines particulares, cuyas características:

1) crean o reconocen derechos e imponen deberes;

2) operan de manera bilateral;

3) son exigibles en contra de extraños; $y$,

4) compensan el daño causado al reclamante, entregando beneficios económicos a la víctima o reivindicando sus derechos.

Para el autor, todas esas características no son distintas cuando la litigación involucra a un ente estatal y, perfectamente, pueden promover una finalidad que enmiende las pérdidas sufridas de forma injusta por un particular ${ }^{34}$.

El camino que Cane propone es la convergencia de los objetivos del derecho administrativo y los del derecho de daños como herramientas funcionales en la responsabilidad extracontractual del Estado ${ }^{35}$. Según

${ }^{32}$ Cane (2014), p. 162.

${ }^{33}$ Cane (2014), p. 162.

${ }^{34}$ Véase Cane (2014), pp. 158-159.

${ }^{35}$ Sin perjuicio de ello, Cane identifica los problemas que Cohen advierte si se toma este camino. Por un lado, estima que la ley de responsabilidad civil está destinada para disuadir a agentes privados, $y$, por lo tanto, no es útil para los agentes del Estado quienes verían frustrada la labor de perseguir el interés público; mientras que, por otro lado, 
esta aproximación instrumentalista, habría que analizar las herramientas de ambas parcelas para determinar una finalidad o propósito específico de la responsabilidad estatal. Con frecuencia se sostiene que los objetivos del derecho de daños son la compensación, la disuasión, la distribución de pérdidas y la igualdad horizontal. En cambio, una de las finalidades en el derecho administrativo es la rendición de cuentas (accountability), que se concibe como un remedio no compensatorio. Esta última es importante en el derecho administrativo, porque permite justificar y legitimar el poder público, cuyo ejercicio en una democracia liberal se encuentra bajo el control de las personas individuales o grupos de personas ${ }^{36}$.

Si bien el derecho administrativo proporciona una serie de herramientas para ejercer este control, Cane sugiere una teoría que destaque la contribución que el derecho de daños puede hacer para legitimar el poder coercitivo del Estado ${ }^{37}$. El aporte conceptual en esta materia es mutuo en las RDJ. Por un lado, el derecho de daños puede entenderse como una herramienta para ejercer control sobre las actuaciones estatales, asegurando los derechos que éste necesita para perseguir el interés público y restringiendo el abuso de poder en detrimento de los ciudadanos. En este sentido, entiende que el régimen de responsabilidad civil provee herramientas útiles para responsabilizar a los agentes públicos en el ejercicio del poder público ${ }^{38}$, por lo que la compensación opera como reacción a la producción de un daño en el incumplimiento de deberes públicos. Por otro lado, el derecho administrativo, mediante la responsabilidad basada en la rendición de cuentas, protege y reconoce derechos que los particulares tienen contra los agentes públicos, que el derecho de daños no reconoce en las relaciones entre privados ${ }^{39}$. En razón de ello, refuerza la posición del particular, quien se encuentra en una situación jurídica desigual frente al agente público.

En términos instrumentalistas, una comprensión extendida del derecho de daños para las RDJ es posible mediante una teoría de la responsabilidad civil de los agentes públicos basada en la rendición de cuentas. Esto asegura que el Estado utilice las vías idóneas para perseguir el interés público y,

la misma ley no contempla criterios de atribución de responsabilidad claros para las infracciones cometidas por agentes públicos, por lo que dejaría sin compensación a las víctimas en algunas situaciones que deberían ser resarcidas. Véase CANE (2014), pp. 159-160.

${ }^{36}$ Véase CAne (2014), p. 164.

${ }^{37}$ Esta posición encuentra su origen en Administrative Law, donde Cane plantea argumentos preliminares que subrayan la importancia de incorporar los remedios monetarios del derecho privado en el ámbito del derecho administrativo. Véase CANE (2011), pp. 299-315.

${ }^{38}$ Véase Cane (2014), p. 164.

${ }^{39}$ Véase Cane (2014), p. 166. 
a su vez, restringe el abuso de poder que ejerce de manera ilegítima en detrimento de los ciudadanos. Para Cane, la ventaja de esta convergencia conceptual se traduce en que

\begin{abstract}
"toma en serio la distinción entre las relaciones de igualdad jurídica y las relaciones de desigualdad jurídica; y que puede adoptar fácilmente regímenes de responsabilidad tanto de derecho público como de derecho privado" 40 .
\end{abstract}

\title{
III. ESTRUCTURA NORMATIVA
}

EN LA RESPONSABILIDAD EXTRACONTRACTUAL DEL ESTADO

La correlatividad es una idea central para determinar la estructura normativa de las interacciones involuntarias. Desde la filosofía del derecho privado, Weinrib acuña un concepto de ésta bajo un modelo de justicia correctiva, que requiere ser justificado mediante consideraciones unificadoras, bilaterales e igualitarias en términos transaccionales. La unidad se verá reflejada si la misma norma se refiere a la ganancia y la pérdida; la bilateralidad es tal en la medida que la ganancia de una parte, es la pérdida de otra; $y$, la igualdad transaccional procederá si la norma no otorga posición preferente a ninguna de las partes en la interacción ${ }^{41}$.

Cada una de estas condiciones pueden ser utilizadas en la responsabilidad extracontractual de manera tal que la pérdida y la ganancia de esta interacción se traduzca, en términos kantianos, como una cuestión de derechos y deberes. Para Weinrib, esto se traduce en que

"[1]a exigencia de que la acción de un individuo sea consistente con la libertad de otro significa que todo agente está obligado a no violar los derechos de los demás" ${ }^{32}$.

De esta manera, la posición kantiana vincula a las partes en la interacción mediante el derecho de quien sufre el injusto y el deber de quien lo causa.

Esta idea de correlatividad se encuentra inserta en la TIE. Sin embargo, presenta dos inconsistencias. La primera se relaciona con el elenco que participa de las interacciones públicas, ya que incorpora a entidades no gubernamentales como a agentes públicos. La segunda se vincula con la distinción entre causante y responsable del daño.

\footnotetext{
${ }^{40}$ Cane (2014), p. 167.

${ }^{41}$ Véase Weinrib (2017), p. 151.

${ }^{42}$ Véase Weinrib (2017), pp. 153-154.
} 


\section{Los participantes en la responsabilidad pública}

En la actualidad, el enfoque funcional predomina en las aproximaciones teóricas para imputar responsabilidad al Estado. En las distintas tradiciones jurídicas podemos ver este fenómeno. En la continental, la teoría del órgano presenta una serie de limitaciones que dificultan la correcta aplicación de la responsabilidad estatal. Sólo la vinculación entre la teoría del órgano y las reglas de responsabilidad pública da como resultado la concepción clásica de esta teoría, la cual se traduce en que el Estado es responsable de los daños causados por el funcionario porque este último actúa como una extensión del órgano estatal ${ }^{43}$. Esta idea no es más que la incorporación de herramientas operativas a la teoría del órgano, ya que desde el funcionamiento de la Administración se demarca con claridad el régimen de responsabilidad que debe ser aplicado en un caso particular ${ }^{44}$.

En la anglosajona, la aproximación funcional también se encuentra presente en la responsabilidad pública. Para Endicott, ésta se sostiene sobre cuatro principios básicos:

1) las autoridades administrativas son responsables de los daños causados por sí mismos (o principio de jerarquía);

2) las autoridades administrativas no gozan de inmunidad por los daños provocados a terceros;

3) las actuaciones ilegales no son en sí mismas un daño, más bien debe existir una razón jurídica para que la víctima sea compensada; y,

4) no hay daño cuando los tribunales tienen que juzgar cuestiones injustificables para sostener la responsabilidad de la autoridad pública $^{45}$.

Los dos primeros indican que los participantes son, por un lado, las autoridades administrativas, $\mathrm{y}$, por otro lado, los ciudadanos o víctimas de los daños causados por los organismos gubernamentales. Los dos últimos muestran que las conductas de las autoridades son el punto central para fijar la responsabilidad pública.

Este enfoque funcional es sostenido por Cane desde Responsibility in law and morality. Sin embargo, el punto innovador que ofrece es que incorpora tanto a entidades gubernamentales como a aquellas que no lo son

${ }^{43}$ Si bien la teoría del órgano ha sido objeto de una serie de matices, en este traajo se considera que logra su mayor poder explicativo en la última edición de la obra de HAUROU (2002).

${ }^{44}$ En Chile, Valdivia descarta que la teoría del órgano se encuentre expresada en ley de bases de la administración chilena, aludiendo a la interpretación errónea que realiza CALDERA (1979) cuando ubica e intenta explicar la operatividad de esta teoría en el derecho administrativo chileno. Véase la crítica en VALDivia (2006), pp. 133-159.

${ }^{45}$ Véase EndicotT (2018), pp. 532-533. 
para establecer el ámbito de la responsabilidad pública. En esta versión, la propuesta del autor indica que la incorporación debe ser entendida en un sentido más bien reducido, esto es, que los organismos no gubernamentales deben ser vistos como delegados del Estado siempre que estos ejerzan una función pública ${ }^{46}$. Si bien la función pública es un punto central en la idea que enarbola Cane para delimitar la frontera entre agentes públicos y privados, aquella postura pierde fuerza cuando no tan sólo incorpora de manera laxa a entidades no gubernamentales, sino que también cuando aparta actividades estatales que considera parte del ámbito privado. El problema se agudiza cuando refuerza su argumentación con ejemplos que diluyen el contorno dispuesto para distinguir entre uno y otro ámbito.

La primera dificultad que es posible identificar se relaciona con la incorporación de organismos no gubernamentales que ejercen funciones públicas. Cane no distingue las singularidades que estos presentan. Si el criterio para definir a los agentes públicos es la función pública que desempeñan, entonces se abre la puerta para que entidades con forma jurídica de derecho privado (por ejemplo: sociedades, universidades, empresas concesionarias de servicios públicos u otros semejantes) puedan entenderse como ocupantes de una posición pública.

Un ejemplo de lo antes señalado sería la conformación de universidades privadas, cuya misión sea servir a la sociedad entregando una formación profesional integral a sus estudiantes. Si tomamos las características generales de un organismo no gubernamental ${ }^{47}$, podríamos conformar una corporación con giro educacional sin fines de lucro y que tenga vocación pública. Esta lógica nos lleva a pensar que una universidad privada es asimilable a un agente público, quien debería responder ante eventuales daños causados en contra de un estudiante por la función pública que desempeña. En estos casos no queda claro qué régimen de responsabilidad se aplica si, por ejemplo, en una obra de construcción dentro de la universidad se desprende material e impacta a un estudiante. Parece contradictorio que el Estado sea responsable de las actuaciones de una entidad que ejerce funciones públicas, pero que no puede controlar. Esto controvierte la necesidad de incorporar organismos no gubernamentales en la responsabilidad pública, cuando en estricto rigor la universidad podría responder civilmente ante el daño causado.

La segunda dificultad se vincula con la idea que intenta demostrar que habría actividades de los órganos gubernamentales que estarían dentro

\footnotetext{
${ }^{46}$ Véase Cane (2011), p. 254.

${ }^{47}$ Según el artículo 71 de la Carta de las Naciones Unidas se define a la ONG como "una agrupación de ciudadanos voluntarios, sin ánimo de lucro, que se organizan en un nivel local, nacional o internacional para abordar cuestiones de bienestar público".
} 
de la esfera privada. El autor señala que no todo lo ejecutado por estos organismos es asimilable a una función pública. El ejemplo que entrega es la de un conductor que debe manejar un automóvil público de un lado a otro, encuadrando dicha función en un plano privado ${ }^{48}$. Esto parece problemático si el conductor que traslada a una autoridad impacta y daña a un transeúnte que cruza la calle. Según Cane, esta interacción no sería una RDJ, sino que más bien una relación de igualdad cuya solución debiese encontrarse en el derecho de daños. Si esto es así, se originan una serie de contradicciones que desvirtúan la función que deben desempeñar los conductores fiscales.

En este punto, Cane minimiza la función de quienes finalmente operan o ejecutan las actuaciones administrativas. El mayor problema es que el límite de la función pública, desde la perspectiva analizada, no hace más que confundir los ámbitos de aplicación de la responsabilidad pública. En estricto rigor, se espera que dicho funcionario traslade a una autoridad desde un lugar a otro sin mayores contratiempos y que no obtenga beneficios propios utilizando un vehículo financiado con recursos públicos.

Nótese que las inconsistencias identificadas no consideran erróneo el marco de referencia propuesto por Cane. El problema no es la distribución de daños según las funciones públicas desempeñadas, sino que más bien la incorporación confusa de participantes para aplicar las reglas de la responsabilidad pública. Esto se presenta como una dificultad porque no habría un sustento jurídico que respaldase la actuación del agente que pertenece a una entidad no gubernamental. Al detenerse en el principio de jerarquía identificado por Endicott, se tiene que el derecho, a través de leyes y estatutos administrativos, impone a la autoridad administrativa una actuación que debe cumplir. En estos casos, se encuentra legitimada para incidir en los intereses de los ciudadanos, ya que una conducta diferente a la satisfacción del interés público la haría incurrir en daños ${ }^{49}$. Sin embargo, ¿cuál sería la defensa de la entidad no gubernamental si es que se alega una actuación negligente? Este tipo de entidades se rigen por normas de derecho privado, que no le imponen el deber de cumplir una función pública. Por lo tanto, no podrían defenderse de las negligencias acusadas indicando que la norma mandataba o imponía una actuación en el marco de la función pública.

En Chile, el régimen de responsabilidad establece la correlatividad entre el Estado y los privados. Expresamente, el artículo $4^{\circ}$ de la ley n. ${ }^{\circ} 18575$ señala que el Estado será responsable ante los daños causados por los órganos de la Administración en el ejercicio de sus funciones. En estos tér-

\footnotetext{
${ }^{48}$ Véase CANe (2014), p. 152.

${ }^{49}$ Véase Endicott (2018), p. 531.
} 
minos, la bilateralidad supone el enfrentamiento entre el ente estatal y los particulares, mientras que la unidad establece que el Estado es responsable del daño causado. Incluir en el ámbito público a una universidad privada por su compromiso social en la educación origina que, ante cualquier daño causado por ella, sea el Estado quien deba resarcir una actuación que no tuvo la posibilidad de controlar. A su vez, apartar al conductor del ámbito público es darle la oportunidad para que satisfaga intereses propios con un vehículo fiscal o que deba responder civilmente por atropellar a una persona que no pudo evitar cuando trasladaba rápido a una autoridad. El enfoque funcional demarca los contornos de aplicación del régimen de responsabilidad y, de paso, entrega herramientas para comprender la operatividad de la responsabilidad estatal.

\section{El causante del daño y el responsable de resarcir}

En la responsabilidad del Estado el causante del daño es distinto de quien responde mediante una compensación. Por lo general, el funcionario público es quien causa el daño a un particular y el Estado quien remedia el injusto cometido. Esta lógica se da siempre y cuando el funcionario actúe dentro de sus atribuciones. Sin embargo, la manera de entender esta lógica

62 relacional varía según la tradición jurídica en que opere la acción en contra del poder público. En el civil law, la responsabilidad recae por regla general en el Estado, y, eventualmente, éste puede proseguir un juicio civil en contra del funcionario que cometió el daño. Desde ahí proviene la clásica distinción del derecho francés entre la falta de servicio y la falta personal. En el common law, recae en el funcionario, quien debe demostrar que actuó dentro de sus atribuciones para que, de manera subsidiaria o vicaria, el Estado se haga responsable de remediar el daño sufrido por la víctima ${ }^{50}$.

En ambos sistemas el funcionario debe responder por el daño causado a la víctima. La diferencia que existe es la posición de quien responde directa y subsidiariamente. Mientras que la responsabilidad pública en el derecho continental se ejerce directamente contra el órgano estatal, en el derecho anglosajón se ejerce indirectamente contra el Estado. En el primero, la lógica es que sea el Estado quien remedie el daño sufrido por la víctima, y quien repita, posteriormente, en contra del funcionario. Para el segundo, la responsabilidad del Estado depende de la comprobación de que el funcionario haya actuado de acuerdo a las funciones públicas encomendadas, por lo tanto, la regla general es que sea el funcionario quien deba enfrentar los juicios en esta materia ${ }^{51}$.

\footnotetext{
${ }^{50}$ Véase FaIrgrieve (2003), p. 25.

${ }^{51}$ Véase Fairgrieve (2003), pp. 23-24.
} 
$\mathrm{Al}$ contrastar estos dos sistemas surge una interrogante, que se relaciona con la razón que justifica que el Estado deba remediar los daños causados por el funcionario público. El derecho continental la responde desde una lógica de inmediatez de la responsabilidad pública. El camino que adopta es la utilización de la teoría del órgano como una herramienta que permite entender que el funcionario es una extensión del órgano estatal. Sin embargo, como se indicó antes, la falencia del argumento de la extensión del órgano es que la teoría que lo sustenta no puede dar cuenta por sí sola de una demarcación funcional entre la aplicación de un régimen público y privado. Este argumento depende de una interpretación que combine tanto la teoría del órgano como las reglas de responsabilidad pública.

Por su parte, el derecho anglosajón responde desde una lógica de comprobación de la responsabilidad pública. La relación entre Estado y funcionario no es una condición suficiente para que la responsabilidad recaiga directamente en el Estado, sino que es necesario que en atención a dicha relación se logre comprobar que el funcionario actuó dentro de sus funciones públicas tal como había sido ordenado. Así, debe acreditarse que el sujeto no actuó fuera de su esfera de atribuciones para imputar responsabilidad pública a la entidad estatal. En Inglaterra, esta lógica relacional es la que mayor adhesión tiene desde la formulación del principio de igualdad de Dicey, quien asimila las actuaciones ejercidas por un agente privado y un agente público ${ }^{52}$.

Desde la otra vereda, Cornford señala que aplicar el principio de igualdad, como lo propone Dicey, no hace más que ocultar la naturaleza pública de los poderes que interactúan con los ciudadanos ${ }^{53}$. Para Cornford, la respuesta correcta para encuadrar la discusión sobre la inmediatez de la responsabilidad pública es a través de la asunción o suposición de responsabilidad. Esta idea, que debe ser entendida en términos amplios, abarca tanto los principios de reciprocidad y confianza entre quien se somete a la órbita organizacional y quien entrega prestaciones, como el principio de dependencia severa, entendido como la relación explícita que existe entre la Administración y el administrado ${ }^{54}$. Según esta explicación, en las RDJ se puede apreciar un componente que debe ser combatido: el daño que se origina en razón de la profunda subordinación estatal.

La interpretación de Cornford reconoce la desventaja que sufre el particular cuando se enfrenta al Estado. Siguiendo esta manera de solucionar los problemas de inmediatez de responsabilidad, la presente investigación se inclina por una TIE que presuma la responsabilidad del Estado, y no en

\footnotetext{
${ }^{52}$ Lo explica con detalle CANE (1999), pp. 489-517.

${ }^{53}$ Véase CORnford (2018), p. 57.

${ }^{54}$ Véase Cornford (2018), pp. 62-67.
} 
el funcionario público. Esta forma de entender las interacciones públicas dota de contenido al artículo $4^{\circ}$ de la Ley de Bases, puesto que fundamenta la inmediatez con la dependencia que sufre el administrado cuando se somete a la esfera organizativa de la Administración. Esto significa que la evaluación que hacen los tribunales sobre la diligencia deba contemplar dos grandes aspectos: el enfrentamiento entre posiciones asimétricas y la capacidad para resarcir monetariamente. En los próximos apartados, se revisarán las razones que justifican la aplicación de un criterio igualitario ante las actuaciones administrativas y el resarcimiento monetario ante daños o lesiones de derechos cometidos por la Administración.

\section{EQUiLIBRIo ENTRE PARTES JURÍdiCAMENTE DESIGUALES}

El argumento que presenta Cane desde las teorías no-instrumentalistas refleja dos cosas:

1) las $\mathrm{RDJ}$ se encuentran presentes en el derecho público y privado; $\mathrm{y}$

2) el derecho de daños debería proporcionar herramientas para solucionar las controversias que se originan en ambas situaciones. No obstante, esta aproximación no identifica correctamente el componente para equilibrar las RDJ en el ámbito público. El Estado y los ciudadanos persiguen distintos planos de intereses, por lo tanto, resulta indispensable abordar desde una perspectiva igualitaria la asimetría de posiciones que ambas partes presentan. El punto de partida será la distinción de los modelos de justicia aristotélicos, luego se expone una manera de armonizar los modelos de justicia correctivo y distributivo y, por último, se establecen los fundamentos teóricos que justifican la incorporación de una perspectiva igualitaria en las RDJ.

\section{La igualdad en los modelos de justicia aristotélicos}

Desde Aristóteles existe una tendencia por vincular el modelo de justicia correctiva con las relaciones entre particulares y el modelo de justicia distributiva con las relaciones entre el sujeto y la sociedad. Esta explicación nos entrega ciertas luces acerca del campo de aplicación de la responsabilidad civil y estatal. De manera simplificada, puede sostenerse que la responsabilidad civil extracontractual es más próxima al primer modelo y la responsabilidad extracontractual del Estado al segundo.

Aristóteles desarrolla el concepto de igualdad a partir de dos modelos de justicia que identifica: la correctiva y la distributiva. En la primera, la igualdad se expresa en términos aritméticos y opera de manera involuntaria cuando 
se produce un daño en un sujeto ${ }^{55}$. Según ella, no importan las características personales de las partes involucradas, por esa razón el derecho velaría porque el daño no altere la igualdad que en abstracto presentan las partes ${ }^{56}$. Este modelo vela por el restablecimiento de la igualdad alterada, es decir, que se retorne la ganancia al afectado que injustamente le ha sido despojada por otro. De esta forma, la corrección busca reprochar al dañador, recomponer la posición del afectado y restablecer el equilibrio entre ambas partes.

Esto último, según Aristóteles, se logra mediante la intervención judicial. El rol del juez en estos casos es equilibrar la ganancia y pérdida de los involucrados en un conflicto, lo cual se explica de tal forma que

"cuando uno recibe y el otro da un golpe, o uno mata y otro muere, el sufrimiento y la acción se reparten desigualmente, pero el juez procura igualarlos con el castigo quitando la ganancia" ${ }^{57}$.

En estos términos, Aristóteles entiende que la ganancia es el golpe que se ha dado y la pérdida es el sufrimiento de quien lo recibe. En esta acción una de las partes se aprovecha de la otra, altera la igualdad entre ambas y el castigo opera como mecanismo de restablecimiento de la igualdad que ha sido lesionada. Según la explicación aristotélica,

"[e]l juez reestablece la igualdad, y es como si de una línea dividida en segmentos desiguales quitara del mayor el trozo que excede de la mitad y lo añadiera al segmento menor. Cuando el todo se divide en dos partes, se dice que cada una tiene lo suyo siempre que ambas sean iguales, y lo igual sea el término medio entre lo mayor y lo menor según la proporción aritmética" ${ }^{58}$.

De esta forma, el juez debe determinar un término medio entre la ganancia y la pérdida para corregir la injusticia sufrida por una de las partes ${ }^{59}$.

En el caso de la justicia distributiva, Aristóteles advierte que ésta se justifica mediante proporciones geométricas ${ }^{60}$. Esto quiere decir que lo

${ }^{55}$ Véase Aristóteles (1985), p. 247.

${ }^{56}$ En palabras de Aristóteles "[n]o importa, en efecto, que un hombre bueno haya despojado a uno malo o al revés, o que un hombre bueno o malo hayan cometido un adulterio: la ley solo mira a la naturaleza del daño y trata ambas partes como iguales, al que comete la injusticia y al perjudicado”. Aristóteles (1985), pp. 247-248.

${ }^{57}$ Aristóteles (1985), p. 248.

${ }^{58}$ Aristóteles (1985), p. 249

${ }^{59} \mathrm{De}$ los ejemplos entregados por Aristóteles se desprende que cuando hace alusión a ganancias y pérdidas se refiere tanto al ámbito civil como al penal.

${ }^{60}$ Véase ARistóteles (1985), pp. 246-247. 
justo será una distribución igualitaria de bienes que debe tener como criterio principal el mérito de aquellos sujetos que participan de una determinada interacción ${ }^{61}$. Para Aristóteles esta forma de entender la igualdad representa dos grandes características. La primera es que la igualdad se logra mediante una distribución proporcionada de un conjunto de bienes o recursos entre los participantes y, la segunda, es que el criterio de distribución debe ser capaz de incorporar los motivos y las circunstancias que rodean a los sujetos en una sociedad para determinar la prioridad en la búsqueda de sus respectivos méritos.

Según esta aproximación, la igualdad proporcionada es una manifestación distinta de la igualdad aritmética. En estricto rigor, la justicia distributiva propone que la igualdad entre los miembros de una sociedad refleje los diferentes planes de vida que cada uno persigue. Sobre esta idea, Aristóteles precisa que dependiendo de sus posiciones en la sociedad, los sujetos persiguen sus propios intereses pues

"no todos coinciden en cuanto al mérito mismo, sino que los demócratas lo ponen en la libertad, los oligárquicos en la riqueza o nobleza, y los aristócratas en la virtud" ${ }^{2}$.

Así, para determinar la igualdad proporcional es indispensable que el criterio distributivo envuelva "una cualidad interna de capacidad, condición, carácter o logros, o una cualidad externa de circunstancia, sea natural o social” ${ }^{63}$ que rodeen al individuo. La búsqueda de justicia mediante una igualdad proporcional supone regular la estructura básica de la sociedad, más allá de las interacciones entre particulares.

Visto así, los casos de responsabilidad extracontractual del Estado se resolverían de mejor manera mediante un modelo de justicia distributiva (igualdad proporcionada). En este tipo de interacciones, la desigualdad se encuentra prestablecida y asumida por quienes han pactado obediencia mutua al ordenamiento jurídico, como un antecedente que advierte del poder que ejerce el Estado sobre la ciudadanía. En dicho contexto, los criterios de distribución resultan indispensables para reducir la distancia entre una y otra posición. Sin embargo, ajustar el análisis de las RDJ sólo a consideraciones distributivas mermaría las explicaciones fijadas sobre la estructura normativa en este tipo de relaciones. Dicho esto, resulta necesario buscar un punto de encuentro entre ambos modelos.

\footnotetext{
${ }^{61}$ Véase ARistóteles (1985), p. 245.

${ }^{62}$ Aristóteles (1985), p. 246.

${ }^{63}$ Benson (1992), p. 535.
} 


\section{La justicia correctiva y la justicia distributiva en la TIE}

La comprensión de la responsabilidad civil extracontractual desde un modelo de justicia correctivo y/o distributivo no resulta ser una cuestión pacífica. Las aproximaciones para interpretar esta parcela del derecho privado muestran dos grandes caminos. En la propuesta de Weinrib, el esfuerzo se centra en comprender las interacciones involuntarias de los privados sólo en razón de las consideraciones correctivas que justifican la reparación a un tercero ${ }^{64}$. Las posiciones antagónicas sugieren cuestionarse si un modelo de justicia correctivo que sirve para establecer la estructura de las relaciones jurídicas es suficiente en este ámbito ${ }^{65} \mathrm{y} / \mathrm{o}$ si es necesario incorporar criterios sustantivos que sean útiles en el plano de la comprensión funcional. Para Papayannis resulta claro que esta parcela del derecho privado debe ser interpretada no tan sólo bajo consideraciones correctivas, sino que también bajo criterios distributivos ${ }^{66}$. Incluso, bajo el prisma del igualitarismo, Keren-Paz aventura una responsabilidad extracontractual que atienda a las posiciones anteriores de las partes involucradas en la interacción para equilibrar las asimetrías de posiciones ${ }^{67}$.

En una aproximación unificadora de la responsabilidad civil extracontractual, Cane intenta compatibilizar la idea de justicia correctiva con su estructura relacional básica y la justicia distributiva con el contenido de las reglas y principios que se encuentran dentro de dicha conformación ${ }^{68}$. Para este autor los modelos son complementarios en el ideario del derecho de daños. Así por lo menos lo considera cuando precisa que la justicia correctiva especifica la estructura del derecho de daños como un sistema de derechos y obligaciones correlativos entre hechores y sufridores de daños, mientras que la justicia distributiva opera dentro de esta estructura especificando en qué consisten estos derechos y obligaciones ${ }^{69}$. Bajo el alero de esta posición, bien podría sostenerse que, por un lado, se consignan las consideraciones correctivas para establecer la estructura normativa en las relaciones privadas, posicionando a las partes con sus derechos y deberes

${ }^{64}$ Véase la propuesta teórica en WEINRIB (2017), pp. 176-199.

${ }^{65}$ Véase una de las principales críticas a las estructuras exclusivamente correctivas en el ámbito de la responsabilidad civil extracontractual en GARDNER (2011), pp. 1-50.

${ }^{66}$ Para dilucidar la manera en que la responsabilidad extracontractual implementa conjuntamente las ideas correctivas y distributivas, véase PAPAYANNIS (2014), pp. 271-348.

${ }^{67}$ Para la comprensión de un enfoque progresivo de la responsabilidad extracontractual, de corte igualitario, que toma en cuenta el efecto distributivo de las reglas para favorecer a los menos privilegiados, véase el marco teórico ofrecido por KEREN-PAZ (2016), pp. 21-41.

${ }^{68}$ Véase CANe (2001), pp. 414-415.

${ }^{69}$ Véase Cane (2001), p. 416. 
correlativos, mientras que, por otro lado, se incorporan consideraciones distributivas que operarían dentro de esta estructura normativa.

En la responsabilidad extracontractual del Estado esta discusión no es ajena. Para Cornford, el modelo de justicia correctivo se encuentra inserto en la estructura de la responsabilidad pública. La explicación recalca la relación bilateral entre quien causa el daño y quien sufre la pérdida. Por esa razón, el autor estima que si una entidad estatal incurre en una carga ilegítima en contra de un privado, la norma jurídica pública debiese corregir ese daño injustificado mediante una reparación pecuniaria ${ }^{70}$. Aunque la dimensión distributiva no está contemplada en esta comprensión de la responsabilidad pública, más bien es posible encontrar elementos que responden a una lógica relacional según lo que Weinrib plantea para la responsabilidad civil.

Desde la responsabilidad estatal, Cane conforma la TIE sobre la base de consideraciones pensadas en un primer momento para el derecho de daños. La similitud estructural entre ambas parcelas permite que la TIE pueda sostenerse sobre la correlatividad y los aspectos funcionales que recaen sobre ella. De esta manera, la relación entre Estado y ciudadanos puede entenderse en clave de derechos y obligaciones correlativas entre partes que se encuentran en disputa, y, a su vez, en relación con las características que rodean esta interacción mediante reglas y principios que precisan su operatividad.

En un sentido similar, Letelier profundiza el vínculo entre las consideraciones correctivas y distributivas en la esfera de la responsabilidad estatal. El autor sostiene que si bien la justicia correctiva ha sido comúnmente utilizada para justificar los objetivos y funciones de la responsabilidad del Estado, los criterios sustantivos extraídos desde la justicia distributiva juegan un papel primordial para comprender de forma completa este ámbito del derecho administrativo $^{71}$. Para el autor es un problema que los tribunales den respuestas jurídicas, o neutrales, a cuestiones que tienen carácter político, ya que la función de los tribunales debiese centrarse en la especificación de los derechos que surgen en las interacciones involuntarias, y no en el simple reconocimiento de derechos ${ }^{72}$. En otras palabras, no basta con tener un acto u omisión estatal contrario a derecho, sino que es necesario que el tribunal evalúe la diligencia de la actuación según ciertos criterios sustantivos.

Letelier expone dos pasos que deben seguir los tribunales para construir correctamente los deberes de cuidado estatales y resolver los casos de responsabilidad pública. Por un lado, sostiene que los tribunales de justicia no sólo están llamados a decidir casos mediante un ejercicio de interpretación restringido, esto es, como meros aplicadores o ejecutores

\footnotetext{
${ }^{70}$ Véase Cornford (2013), pp. 131-132.

${ }^{71}$ Véase Letelier (2010), p. 11.

${ }^{72}$ Véase Letelier (2010), p. 12.
} 
de la norma jurídica. En el ámbito de la responsabilidad pública, la interpretación judicial debe resolver casos donde se debe especificar, por ejemplo, el alcance del interés público. El ejercicio interpretativo debe encontrar un contenido posible para un concepto indeterminado que la norma jurídica no es capaz de precisar por sí sola ${ }^{73}$. Por otro lado, Letelier advierte que una manera de completar la construcción de deberes de cuidados es mediante la aplicación de criterios distributivos. Según el autor, en la responsabilidad pública los tribunales debiesen resolver casos utilizando argumentos creados mediante criterios sustantivos. Precisamente, las consideraciones distributivas se perfilan como una fuente argumentativa que da contenido a los conceptos oscuros de una norma. Si uno de los participantes es el Estado, entonces el deber de cuidado o la obligación estatal debiese definirse, mediante un alcance distributivo, según la magnitud de la falta cometida ${ }^{74}$.

Un análisis formal que busca corregir perjuicios no parece suficiente para examinar la diligencia de una actuación administrativa. Por esta razón, la aplicación de criterios sustantivos y particulares como, por ejemplo, aquellos que analizan las circunstancias concretas que rodean las RDJ, resultan imprescindibles para establecer la responsabilidad del Estado. La utilización de criterios distributivos permite que los tribunales evalúen con mayor precisión la obligación que posee el Estado respecto de los administrados. Uno de esos criterios debería ser el criterio igualitario, entendido como un componente que equilibra las posiciones de asimetría que existen en las RDJ.

\section{Equilibrio entre partes jurídicamente desiguales}

Los intereses entre las partes que interactúan en el ámbito público no tan sólo son distintos, sino que también contrapuestos. Esto hace que las posiciones normativas entre el Estado y los ciudadanos se desarrollen en un plano de asimetría. Mientras los particulares ejercen su libertad para satisfacer sus propios planes de vida, las entidades estatales ejercen su poder político para satisfacer el interés público, incluso, interviniendo de manera legítima en los intereses particulares de la ciudadanía.

Sin embargo, la subordinación estatal no puede ser vista de manera homogénea. Para Fiss, la dominación que sufren ciertos grupos de personas se refleja a través de tres características. La primera, se relaciona con la pertenencia a un grupo social específico; la segunda, con la desventaja sufrida por un período de tiempo prolongado; $y$, por último, con que el ejercicio

\footnotetext{
${ }^{73}$ Véase Letelier (2010), p. 13.

${ }^{74}$ Véase Letelier (2010), p. 14.
} 
del poder político del grupo se encuentre severamente limitado ${ }^{75}$. Una forma de reflejar la posición desfavorecida en una RDJ es la ubicación social que ocupan las personas en la sociedad, ya sea por su género, raza o etnia, capacidad económica, discapacidad física, sector etario y/o estatus jurídico.

En los términos de Fiss, esto quiere decir que la aplicación del criterio igualitario es variable. El rendimiento depende de quien enfrente al Estado, si un particular aventajado o desaventajado. Respecto del último caso, las decisiones judiciales debiesen aplicar el criterio igualitario para restablecer la desventaja injustificada que un modelo correctivo no logra corregir. El autor llama proceso de asimilación a la protección de derechos e intereses que ayuda a que desaparezca la desventaja del grupo o, en su defecto, mejore las capacidades políticas, sociales y/o económicas de sus miembros ${ }^{76}$.

Desde Rawls se suele sostener que en estos casos los bienes sociales primarios han sido distribuidos de manera desigual, por lo tanto, resulta necesario incorporar desde el derecho medidas igualitarias que logren equilibrar las relaciones desiguales que surgen en una sociedad ${ }^{77}$. En este escenario, las teorías igualitarias vienen a reivindicar los principios que expresan igual consideración y respeto por todos los ciudadanos. Se trata de aproximaciones que buscan terminar con un desequilibrio involuntario de quien lo sufre $y$, en razón de ello, intentan restablecer la capacidad para decidir con libertad lo que se desea. Esta manera de enfrentar el problema de la desigualdad supone que habrá casos donde la pérdida, irremediablemente, tendrá que ser asumida por la víctima. No obstante, la frontera que demarca la pérdida indemnizable presenta algunos matices que dependen de la teoría igualitaria adoptada. Las versiones que intentan dar cuenta de esta problemática son dos: el igualitarismo de la suerte ${ }^{78}$ y la igualdad democrática.

${ }^{75}$ Véase Fiss (1999), p. 144.

${ }^{76}$ Véase Fiss (1999), p. 145.

${ }_{77}$ Véase RAWLS (1995), pp. 69-70. Para el autor, los bienes sociales primarios deben distribuirse de manera semejante en derechos y deberes. Ahora, si en esa distribución se produce una desigualdad que mejora las condiciones de vida de las personas más desfavorecidas, entonces debería permitirse esa medida.

${ }^{78}$ Esta aproximación presenta matices respecto de los ámbitos desde dónde se defienden. Por un lado, se encuentra la facción que acepta la transferencia de recursos de tal forma que las personas quedan igualadas en su bienestar. Véase Arneson (1990); CoHen (1995); Roemer (1994); y, Nagel (1991). Mientras que, por otro lado, está la facción que promueve que exista responsabilidad por las elecciones personales que permita distinguir entre quienes deben beneficiarse del esquema distributivo y quienes no. Véase DwORKIN (1981a); DwORKIN (1981b); RAKOWSKI (1991); y, vAN PARIJS (1991). De esta forma, estas posiciones intentan resolver cuestiones tales como: la razón que tuvieron los desventajados para estar en esa posición y los mecanismos que se deben utilizar para la redistribución de recursos. Esta posición se cobija en una interpretación rawlsiana para asumir dos aspectos centrales: 1) que debe compensarse a los individuos por la mala suerte inmerecida; y, 2) que la compensación debe ser transferida desde quienes han obtenido bienes inmerecidamente. Véase RAwLS (1995), pp. 103-110. 
Esta investigación se inclina por la teoría de la igualdad democrática desarrollada por Anderson para definir el criterio igualitario en las RDJ. Para la autora, la finalidad principal de la igualdad debiese ser asegurar la libertad de todas las personas y acabar con la opresión social ${ }^{79}$. Esta pretensión muestra, en términos positivos, que la igualdad se debe reflejar en las relaciones entre personas con las mismas capacidades, y, en términos negativos, que se busca abolir cualquier tipo de vínculo que presente rasgos de dominación, explotación y/o marginalización ${ }^{80}$. La relación entre individuos superiores e inferiores es una de las características de la opresión social, más aún cuando se expresa en marginalización, jerarquía de estatus, dominación, explotación e imperialismo cultural ${ }^{81}$. En estos términos, la distancia que marca la igualdad democrática es que no se presenta como una teoría moralizante que evalúa aspectos subjetivos, sino que más bien como una teoría que busca igualar las capacidades jurídicas entre los miembros de la sociedad ${ }^{82}$.

En razón de ello, los elementos que destaca Anderson para conformar un concepto de igualdad democrática son:

1) la garantía de condiciones mínimas para desempeñarse como un ciudadano libre en una comunidad política;

2) el posicionamiento de una teoría relacional, en donde las capacidades de los miembros de la sociedad son su preocupación principal para concebir una relación entre personas que se exigen cosas recíprocamente; y,

3) la distribución de bienes de acuerdo a principios y procesos que expresan respeto por todos ${ }^{83}$.

Esta conceptualización abre dos grandes preguntas. La primera indica ¿qué es aquello que se debe igualar? En esto, Anderson adhiere a la postura de Sen, quien sostiene que una teoría igualitaria debe perseguir la igualdad para todos en el ámbito de las capacidades. Una persona goza de una mayor libertad mientras mayor sea el rango de oportunidades que efec-

${ }^{79}$ Véase Anderson (1999), p. 312.

${ }^{80}$ Véase Anderson (1999), p. 312.

${ }^{81}$ En estos términos, véanse las manifestaciones de la opresión social que devela Young (1990).

${ }^{82}$ En este punto, Anderson critica el camino que utiliza el igualitarismo de la suerte para enfrentar el problema de la desigualdad. Las dificultades que identifica se relacionan con los aspectos moralizantes que esboza esta interpretación de la igualdad. Por ejemplo, dictando a las personas cómo usar sus oportunidades y evaluando el nivel de responsabilidad de las personas en aquellas elecciones que llevan a resultados negativos. Véase ANDERSON (1999), pp. 308-311. Esto se agudiza cuando el foco de atención se centra en redistribuir bienes desde personas superiores a otras catalogadas como estúpidas, poco talentosas, amargadas y/o feas. Véase NAGEL (1979), pp. 91-105.

${ }^{83}$ Véase Anderson (1999), p. 313. 
tivamente posee para conformar su plan de vida de la manera que mejor estime. La idea de capacidad permite que las personas se encuentren en un plano de igualdad para perseguir libremente sus intereses particulares ${ }^{84}$.

La segunda pregunta señala cंcuáles serían las capacidades que la sociedad debiese igualar? La autora identifica tres aspectos que garantiza la igualdad democrática respecto de la estructura de las capacidades:

1) acceso efectivo a niveles de funcionamiento;

2) acceso a niveles de funcionalidad suficientes para el posicionamiento igualitario dentro de la sociedad; $y$,

3) acceso efectivo a un conjunto de capacidades suficientes durante el transcurso de una vida.

En cuanto al primero de ellos, Anderson señala que el acceso a un nivel de funcionalidad significa que los individuos pueden alcanzarlo al desplegar medios que ya se encuentran a su disposición ${ }^{85}$. En este plano, la igualdad democrática articula un sistema de incentivos que propone la posibilidad de acceder a bienes, siempre que la persona desee hacerlo. Por ejemplo, nada impide que una persona pueda atenderse en el servicio público de salud, salvo que elija ser parte de una congregación religiosa que desaconseja ciertas intervenciones médicas ${ }^{86}$.

Respecto al segundo aspecto, Anderson asume una posición moderada. La idea de garantizar un conjunto de capacidades suficientes es objeto de una interpretación amplia, y lleva a preguntarse por el alcance que tiene la expresión capacidades suficientes. Sin lugar a dudas, es una cuestión debatible, ya que no todas las funcionalidades requieren los mismos niveles de capacidad. Lo cierto es que deben abarcar un mínimo determinado que permita el ejercicio de derechos y desarrollo de las personas en la sociedad en un plano de igualdad sustantivo ${ }^{87}$. En este sentido, un simulacro militar debe contemplar una serie de medidas destinadas para que no exista ningún lesionado; desde el transporte, hasta la utilización de armamento adecuado para no sufrir ningún daño grave en la integridad física de los participantes.

Por último, Anderson precisa que

"la igualdad democrática garantiza acceso efectivo a un paquete de capacidades suficiente para pararse como un igual frente a otros durante el transcurso de una vida" ${ }^{88}$.

${ }^{84}$ Véase Anderson (1999), p. 316, citando a Sen (1992), pp. 39-42.

${ }^{85}$ Anderson (1999), p. 318.

${ }^{86}$ Sobre la responsabilidad estatal que se originan por transfusión de sangre y alimentación forzada, véase Poblete (2019), pp. 33-36

${ }^{87}$ Véase Anderson (1999), p. 319.

${ }^{88}$ Anderson (1999), p. 319. Traducción propia. 
Este conjunto permite que una persona pueda posicionarse frente a miembros de la sociedad con las mismas herramientas. La particularidad de esta visión, a diferencia del igualitarismo de la suerte, es que la fortuna no juega un rol protagónico, por lo tanto, la mala suerte de haber tomado una decisión con consecuencias negativas no obstruye a aquella persona de la posibilidad de gozar del conjunto de capacidades suficientes a lo largo de su vida. La igualdad democrática garantiza capacidades inalienables que perduran en el tiempo, derechos que se mantienen vigentes $\mathrm{y}$ disponibles para ser ejercidos por sus destinatarios ${ }^{89}$. De esta forma, si una persona comete un delito, cualesquiera sean las razones que tuvo para hacerlo, aquello no obsta a que deba ser juzgada con todas las garantías de un debido proceso.

En el ámbito del derecho administrativo, el conjunto de capacidades suficiente depende del sector regulado analizado. La particularidad de los servicios, en su orgánica y funcionamiento, permite identificar, en algunos casos, desigualdades ilegítimas y la necesidad de incorporar dosis igualitarias. Por ejemplo, el sistema de responsabilidad por falta de servicio de la ley n. ${ }^{\circ} 19966$ (GES) es parcialmente especial en relación con la Ley de Bases de la Administración. Esta relación de especialidad implica que el juez tiene una carga de argumentación muy precisa: debe integrar los principios de acceso, oportunidad, costo y equidad del sistema sanitario al juicio de imputación de responsabilidad, pues este es el único modo de interpretar e integrar la cláusula falta de servicio de forma coherente con la legislación sanitaria. En este contexto, la perspectiva igualitaria busca garantizar que los particulares tengan acceso permanente y efectivo a un conjunto de medidas sanitarias costosas, propiciando un acceso a la salud y reduciendo el sometimiento a la esfera organizativa de la Administración ${ }^{90}$.

Por su parte, la falta de servicio en contextos carcelarios también responde a una especialidad en razón de la relación jurídica penitenciaria. En este ámbito, la interacción se caracteriza por la confrontación constante entre los derechos de los reclusos y el deber de cuidado estatal. La dificultad que presenta esta fricción es que la intervención estatal está propensa a ser negligente, ya que los privados de libertad están sometidos a fuertes medidas de vigilancia. Esto supone una intervención estatal intrusiva que merma la capacidad de los reclusos para ejercer, por ejemplo, sus derechos en salud, integridad física y privacidad. De esta forma, el paquete de capacidades suficiente debe estar compuesto por medidas que logren

${ }^{89}$ Véase Anderson (1999), p. 320.

${ }^{90}$ Sobre la falta de servicio en la ley n. 19966 (GES), véase AgüEro et al. (2020), pp. 171-191. En estos términos, véase A. F. con Servicio de Salud de Talcahuano (2018) y B. U. con Servicio de Salud de la Región del Libertador Bernardo O’Higgins (2017). 
armonizar la posición jurídica de los presos y las condiciones materiales de vida en las que se encuentran en las cárceles. Esto se traduce, por un lado, en la vigilancia apropiada por haber incumplido el derecho penal y, por otro lado, en la idea de brindar herramientas para que las capacidades jurídicas de los internos no se vean disminuidas considerablemente ${ }^{91}$.

\section{LA CONVERGENCIA INSTRUMENTAL DEL DERECHO ADMINISTRATIVO Y EL DERECHO DE DAÑOS}

La última dificultad que se puede avizorar es la falta de una explicación para esclarecer el carácter compensatorio de la rendición de cuentas. En este punto no se entregará una respuesta alternativa, sino que se profundizará la estipulación plural esbozada por Cane en su formulación teórica. En lo que sigue, este trabajo centrará su atención en el análisis del carácter enmendador que implícitamente se encuentra inserto en la rendición de cuentas estatal y, a partir de ello, se vincularán conceptualmente los objetivos del derecho administrativo y de daños. Sin perjuicio de ello, antes se fijarán los nuevos paradigmas del derecho público que el mismo Cane desarrolla previamente en su obra Responsibility in Law and Mora$74 \quad$ lity.

\section{Los paradigmas del derecho público: entre derecho civil y derecho penal}

Para Cane los propósitos del derecho público se posicionan entre los objetivos del derecho civil, en cuanto a la prevención y reparación el daño, y los objetivos del derecho penal, en especial la disuasión de ciertos tipos de conducta que conforman la configuración de tipos penales ${ }^{92}$. En esta materia, Cane entiende que el derecho público centra su análisis en el desempeño de las funciones públicas que emanan de la Administración y que son ejecutadas por sus autoridades y funcionarios. Para este autor el derecho público se ocupa por un lado de las funciones, estructura, organización y procesos de los funcionarios públicos; y, por otro lado, se centra en la regulación, control y revisión en el ejercicio de las funciones

\footnotetext{
${ }^{91}$ Sobre los deberes de custodia y resguardo en la actividad penitenciaria, véase POBLETE (2019), p. 25-29. En L. H. con Fisco de Chile (2012), la Corte Suprema responsabilizó al Estado por una negligencia médica sufrida por un recluso. En la argumentación, la Corte destacó que el recluso sufrió la amputación de una pierna por una atención médica tardía, lo cual limitó su fuerza laboral en libertad y comprometió su reinserción social. En un mismo sentido argumentativo, véase M. G. con Gendarmería de Chile (2020).

${ }^{92}$ Véase Cane (2002), p. 251.
} 
públicas cuando define y aplica las obligaciones que poseen los funcionarios públicos ${ }^{93}$. Esta dualidad de perspectivas funcionales, nos permite delimitar el campo del derecho público en temas de responsabilidad.

La perspectiva que interesa en este trabajo es la segunda, principalmente, porque ayuda a dilucidar las actuaciones que son objeto de ser resarcidas según las funciones públicas ejercidas. A diferencia de lo que ocurre en el derecho penal y civil, que centran su atención en la disuasión de conductas y el resarcimiento a individuos particulares, el derecho público, mediante el principio de legalidad, evita que instituciones públicas tomen decisiones fuera del interés público perseguido. Esta diferencia es relevante porque demuestra que en este régimen la responsabilidad es estricta y, por consiguiente, la culpa posee rasgos diferentes en esta parcela. Este elemento en el derecho penal es determinante a la hora de fijar si, por ejemplo, una actuación reviste un delito de hurto o robo; en el caso del derecho civil por regla general la culpa también juega un rol central para determinar ilícitos civiles, como son los casos de daños o perjuicios patrimoniales o extrapatrimoniales.

En este punto, lo central es destacar el campo en el que se posiciona el derecho público, en particular el derecho administrativo, respecto del derecho civil y el derecho penal. La reubicación de los paradigmas del derecho público permite fijar un punto de referencia para la vinculación instrumental que se pretende desarrollar, entre el objetivo reparador o compensatorio del derecho de daños y el objetivo explicativo que propone el derecho público mediante la rendición de cuentas. En lo que sigue se ofrece una explicación que logre dar contenido al aspecto enmendador de la rendición de cuentas y, con ello, satisfacer la vinculación conceptual de ambos objetivos.

\section{Deberes derivados de la responsabilidad por rendición de cuentas (accountability)}

La rendición de cuentas tiene un alcance sobre todas las actividades públicas. El ámbito de aplicación es amplio y comprende todas las actuaciones que derivan de la función pública, dentro de ellas las actuaciones administrativas ${ }^{94}$. En esta materia, Oliver entiende que la rendición de cuentas en el ámbito público es

"estar obligado a dar cuentas o explicaciones de las acciones y, cuando corresponda, a sufrir las consecuencias, asumir la culpa o

${ }^{93}$ Véase CANE (2002), p. 252.

${ }^{94}$ Los diferentes ejemplos de accountability, véanse en EnDICOTT (2018), p. 589. 
el compromiso de restablecer los derechos si pareciera que se han cometido errores" ${ }^{\prime 2}$.

Esta conceptualización entrega una aproximación adecuada para abordar el análisis de la rendición de cuentas en relación con los deberes contenidos en las actuaciones estatales. El estudio de Oliver desarrolla los deberes involucrados en esta materia, pero no diferencia entre una y otra obligación. Es por esa razón que puede distinguirse entre deberes de aclaración, como aquellas obligaciones que tiene el Estado de explicar y justificar sus actuaciones ante la ciudadanía, y deberes de enmienda, que son las obligaciones de restablecer jurídicamente a quien, por alguna actuación estatal, ha sufrido lesiones en sus derechos o daños en los intereses perseguidos.

En cuanto a los deberes de aclaración, Oliver considera que

"la rendición de cuentas implica, en este contexto, un deber legal, político, social o moral por parte de un agente público de explicar y justificar su acción o inacción ante particulares que exigen explicaciones de acuerdo con los estándares establecidos o asociados con su posición de ciudadanos" ${ }^{\prime}$.

76 Dicho esto, la rendición de cuentas puede ser contemplada de dos maneras distintas dependiendo de la posición en la que se encuentren los involucrados. Por un lado, el deber que tiene el agente público de actuar de acuerdo con el interés público y, por otro lado, el derecho que tiene el ciudadano de exigir actuaciones que no involucren el interés particular de quien ejerce una función pública.

En palabras de Oliver, la actuación estatal debe estar revestida de altruismo a la hora de ejercer las funciones que el cargo público exige, lo cual es inverso a la idea de satisfacción de los intereses personales por medio de aprovechamiento de recursos públicos ${ }^{97}$. Un Estado de derecho liberal debe contemplar dos grandes pilares que garanticen que el deber de aclaración no sea incumplido de manera arbitraria por quien ejerce a autoridad: el interés y la función públicos. Precisamente, el interés público es la finalidad que debe ser alcanzada por medio de la función pública, cuyo estándar de diligencia se asocia con las actuaciones de los funcionarios públicos o autoridades según las atribuciones normativas derivadas del cargo que ejerce ${ }^{98}$.

\footnotetext{
${ }^{95}$ Oliver (1991), p. 22. Traducción propia.

${ }^{96}$ Oliver (2013), p. 289. Traducción propia.

${ }^{97}$ Véase Oliver (2013), p. 289.

${ }^{98}$ En los mismos términos, véase Ponce (2019), p. 25.
} 
En cuanto a su ámbito de aplicación, Oliver considera que la rendición de cuentas se aplica a autoridades, sean de elección popular o no, funcionarios y otros agentes que ejercen funciones públicas ${ }^{99}$. En este orden de cosas, los obligados no tan sólo son aquellos quienes deben su posición por una elección directa de los ciudadanos, sino que también se obliga a todos los agentes designados o contratados que prestan un servicio público. En un primer nivel, las obligaciones que surgen de la rendición de cuentas consideran que el aparataje público se controle por sí mismo. El principio de pesos y contrapesos demuestra que si existe una actuación injustificada del poder ejecutivo, eventualmente, sea el poder legislativo o el judicial quien ejerza un control sobre dicha actuación. En un segundo nivel, las obligaciones que emanan del aparato público son controladas por los ciudadanos para no sufrir lesiones por actuaciones injustificadas del Estado.

Desde la concepción que el mismo Oliver entrega de rendición de cuentas se pueden extraer e interpretar los deberes de enmienda. En una primera acepción, enmendar se refiere a la acción de arreglar o quitar un defecto. En general, se puede entender que el Estado se encuentra obligado a arreglar un mal que produjo con su actuación y debe revertir la lesión de derechos producida. En una segunda acepción, la palabra hace alusión a resarcir o subsanar daños, típica del derecho de daños. Desde la responsabilidad extracontractual del Estado esta interpretación resulta relevante, puesto que Oliver entrega una noción de rendición de cuentas que contiene un elemento enmendador que se puede interpretar según esta segunda acepción. De esta forma, el Estado que produce un mal en un ciudadano o particular debe revertir la situación de afectación resarciendo el daño producido, que según el derecho de daños debiese traducirse en una indemnización de perjuicios.

Este elemento logra ser identificado por Harlow, quien vincula conceptualmente la rendición de cuentas estatal y la responsabilidad civil extracontractual. La autora nota que la definición de rendición de cuentas entregada por Oliver tiene un elemento enmendador cuando hace alusión al "compromiso de restablecer los derechos si pareciera que se han cometido errores" 100 . Para Harlow esta definición es clave, porque entrega una comprensión total de las dimensiones de la rendición de cuentas y, por consiguiente, identifica la manera de enmendar aquellos perjuicios sufridos por la víctima. En este sentido, el deber de enmendar se encontraría implícito en la rendición de cuentas, puesto que impone un deber en el agente público que ha cometido un acto negligente o incurrido en una omisión indebida. Visto así, la Administración no sólo se obliga con

\footnotetext{
${ }^{99}$ Véase Oliver (2013), p. 289.

${ }^{100}$ Harlow (2004), p. 51. Traducción propia.
} 
los ciudadanos a actuar de manera diligente rindiendo explicaciones si las acciones indebidas así lo ameritan, sino que también se compromete a la reparación pecuniaria de todos aquellos daños que se generan producto de su actuación ilegítima.

Estos deberes parecen suficientes para que los ciudadanos puedan limitar la actuación coactiva del Estado. Sin embargo, más allá de la interpretación extensiva que se identificó en este trabajo, la rendición de cuentas no estipula un mecanismo para restablecer el derecho o resarcir el daño causado por las actuaciones indebidas de la Administración. La interpretación que hace Harlow sobre el aspecto enmendador de la rendición de cuentas no especifica los tipos de daños que se debiesen reparar ante la existencia de un daño o vulneración de derechos. En este punto la irrupción del derecho de daños comienza a ser importante para determinar la responsabilidad de la Administración mediante el remedio compensatorio que ofrece la responsabilidad civil extracontractual: la indemnización de perjuicios. Si bien el derecho administrativo reconoce derechos a los particulares mediante la rendición de cuentas para ejercer un límite al poder coercitivo del Estado, el derecho de daños entrega las herramientas para ejercer dichos derechos mediante la responsabilidad extracontractual.

En estos términos, se reformulan los objetivos de la responsabilidad extracontractual del Estado. La rendición de cuentas estatal se presenta como un mecanismo que incorpora la dimensión compensatoria, por lo tanto, el Estado debe resarcir ante la producción de un daño. Precisamente, el elemento enmendador no lo desarrolla Cane para explicar la convergencia instrumental de los objetivos del derecho administrativo y derecho de daños ${ }^{101}$. No logra identificar que en ambos objetivos existe un carácter enmendador. Mientras que en el primero está presente de forma implícita en la ley que contempla la rendición de cuentas, en el segundo se encuentra explícito en la ley de responsabilidad extracontractual. De esta forma, en cuanto a la idea original de Cane sobre la visión instrumental pluralista de la rendición de cuentas, es posible afirmar que la ley no tan sólo obliga a la Administración a dar explicaciones sobre sus actos mediante los deberes de aclaración, sino que también a restablecer derechos o compensar perjuicios causados injustificadamente a terceros por medio de los deberes de enmienda.

${ }^{101} \mathrm{Al}$ autor no parece inquietarle mayormente este aspecto, pues en su trabajo asume que el common law carece de una distinción categórica y arraigada institucionalmente entre el derecho público y el derecho privado. Véase CANE (2014), p. 168. Es por ello por lo que cualquier problema que surja en aquella zona se debe al problema fronterizo que se evidencia entre ambas ramas del derecho. 
Este enfoque instrumentalista pluralista sirve, en general, para repensar los paradigmas del derecho público y, en particular, para permear en los objetivos de la responsabilidad extracontractual del Estado mediante la compensación monetaria. Esto explica la vinculación entre los daños cometidos por el Estado y el consiguiente deber de resarcir. Si se entiende la falta de servicio como un símil de la culpa civil, entonces la reformulación desarrollada es útil para entender la incorporación de la indemnización de perjuicios como un remedio compensatorio disponible en el régimen de responsabilidad público nacional. En esto, el artículo 42 de la Ley de Bases no entrega muchas pistas, ni elementos para sostener ello, aunque el argumento entregado hasta acá posee la precisión conceptual necesaria para afirmar la convergencia instrumental entre los objetivos de ambas parcelas del derecho.

\section{Conclusiones}

El presente trabajo analizó la influencia del derecho de años en la conformación y comprensión del régimen de responsabilidad por falta de servicio chileno. Para dar cuenta de ello, se descompuso la propuesta teórica de Cane y, posteriormente, se entregaron argumentos que consolidan el marco teórico que debiese ser aplicado en las RDJ originadas en las hipótesis de responsabilidad extracontractual del Estado.

La primera dificultad que se evidenció es la idea de correlatividad que se encuentra inserta en la TIE. Cane identifica que en las RDJ el agente privado tiene el derecho a ser remediado ante el daño sufrido y que el agente público tiene el deber de reparar el perjuicio causado. Sin embargo, esta confrontación supone incorporar entidades no gubernamentales como agentes públicos siempre que desempeñen funciones públicas. El problema de esta incorporación es que el Estado no posee ningún control sobre estas $y$, ante un eventual daño, debería responder con fondos fiscales una actividad de carácter privado. Para resolver esta inconsistencia de la TIE, por un lado, se descartó que las entidades no gubernamentales sean consideradas como agentes públicos y, a su vez, que los funcionarios públicos sean contemplados como agentes privados cuando desempeñan labores menores (como es el caso de los conductores); $y$, por otro lado, se establecieron las razones por las cuales el responsable del daño debiese ser el Estado y no el causante del daño, que en estos casos es el funcionario público.

La segunda dificultad que se identificó aborda el componente generador de equilibrio entre partes jurídicamente desiguales. Para Cane este componente se logra con la vinculación conceptual entre el principio de 
igualdad y el de proporcionalidad. El argumento que se presentó para contrastar esta explicación supuso analizar el principio de igualdad desde la perspectiva de la asimetría de posiciones. De esta manera, se sostuvo que el equilibrio se logra si la igualdad es analizada desde la justicia distributiva en términos geométricos, y no sólo desde la justicia correctiva en términos aritméticos. El estudio realizado desde esta vereda permite descubrir las condiciones cualitativas que cada parte presenta. Por un lado, se logra evidenciar el grado de poder que tiene el Estado cuando interviene en los intereses propios perseguidos por los miembros de la sociedad y, por otro lado, la desventaja que presentan los agentes privados debido a la intervención estatal que limita la prosecución de su plan de vida. Desde esta perspectiva, la igualdad busca reducir la subordinación estatal cuando existe una interacción pública que involucra el sometimiento del administrado en la esfera organizacional de la Administración.

Por último, se sostuvo que el argumento entregado por Cane para asimilar los objetivos del derecho administrativo (rendición de cuentas) y el derecho de daños (compensación) carece de profundidad. Para contrarrestar este vacío se armonizaron los objetivos reubicando los paradigmas del derecho público entre el derecho civil y el derecho penal, y reinterpretando el carácter compensatorio de la responsabilidad por rendición de cuentas. Esta conclusión se pudo extraer de la distinción que se hizo entre deberes de aclaración, que consisten en la explicación de una actuación, y deberes de enmienda, que consisten en la obligación de enmendar o restablecer los derechos lesionados de un tercero o, de manera más precisa, resarcir los daños ocasionados a un particular. Esta interpretación da cuenta de una explicación instrumental pluralista que incorpora la compensación en la responsabilidad por rendición de cuentas.

Los argumentos entregados permiten concluir que el derecho de daños ha asumido un rol importante para la comprensión del régimen de responsabilidad estatal por falta de servicio en Chile. Específicamente, el derecho de daños ha funcionado como una caja de herramientas conceptuales desde donde se obtienen los elementos básicos para modelar una teoría que da cuenta de las particularidades que se presentan en el ámbito público. Resulta evidente que el derecho de daños no puede ser trasplantado complemente al derecho administrativo, aunque su contribución resulta útil y necesaria para conformar una teoría de los ilícitos estatales.

\section{Bibliografía CITADA}

Agüero, Claudio, Sebastián Sandoval y Juan Pablo Zambrano (2020). "La falta de servicio en la Ley $\mathrm{N}^{\circ} 19.966$ (GES)”. Ius et Praxis, año 26, n. ${ }^{\circ}$, Talca. 
Anderson, Elizabeth (1999). "What is the point of equality?". Ethics, 109, Chicago. Aristóteles (1985). Ética Nicomáquea. Madrid: Gredos.

Arneson, Richard (1990). "Liberalism, Distributive Subjectivism, and Equal Opportunity for Welfare". Philosophy and Public affairs, vol. 19, n. ${ }^{\circ}$ 2, Princeton, New Jersey.

Barros, Enrique (2020). Tratado de responsabilidad extracontractual. $2^{\text {a }}$ edición. Santiago: Editorial Jurídica de Chile, tomo I.

Beever, Allan (2007). Rediscovering the Law of Negligence. Oxford: Hart Publishing. Benson, Peter (1992). "The basis of Corrective Justice and Its Relation to Distributive Justice". Iowa Law Review, 77 (2), Iowa.

Cane, Peter (2014). "Tort Law and Public Functions", en John Oberdieck. Philosophical Foundations of the Law of Torts. Oxford: Oxford University Press.

Cane, Peter (2011). Administrative Law. 5a ed. Oxford: Oxford University Press.

CAnE, Peter (2002). Responsibility in law and morality. Oxford-Portland Oregon: Hart Publishing.

Cane, Peter (2001). "Distributive Justice and Tort Law". New Zealand Law Review, n. ${ }^{\circ} 401$, Auckland.

Cane, Peter (1999). "Damages in Public Law”. Otago Law Review, vol. 9, n. ㄱ, Otago.

Caldera, Hugo (1979). "Teoría del órgano, Estado de derecho y responsabilidad del Estado: notas sobre su formulación en el derecho chileno". Revista de Derecho Público, n. ${ }^{\circ}$ 25-26, Santiago.

Cohen, Gerald (1995). "Incentives, Inequality, and Community", en Stephen Darwall (ed.). Equal Freedom. Ann Arbor: University of Michigan Press.

Cordero, Luis (2019). Responsabilidad extracontractual de la administración del Estado. $2^{\mathrm{a}}$ ed. Santiago: DER Ediciones.

Cornford, Tom (2018). "Assumption of responsibility by public authorities". The Denning Law Journal, vol. 30, Buckingham.

CORnFord, Tom (2013). "The public law dimension of public authority liability". The Denning Law Journal, vol. 25, Buckingham.

CORnford, Tom (2008). Towards a public law a tort. Aldershot: Ashgate Publishing.

DwOrkin, Ronald (1981a). "What is Equality? Part 1: Equality of Welfare". Philosophy and Public Affairs, vol. 10, n. ${ }^{\circ}$ 3, Princeton, New Jersey.

Dworkin, Ronald (1981b). "What is Equality? Part 2: Equality of Resources". Philosophy and Public Affairs, vol. 10, n. ${ }^{\circ} 4$, Princeton, New Jersey.

EndicotT, Timothy (2018). Administrative Law. $4^{\mathrm{a}}$ ed. Oxford: Oxford University Press.

Fairgrieve, Duncan (2003). State Liability in Tort. Oxford: Oxford University Press.

FerradA, Juan Carlos (2020). "La responsabilidad patrimonial del Estado de Chile: una revisión panorámica después de casi veinte años de jurisprudencia de la Corte Suprema”. Revista de Administración Pública, n. ${ }^{\circ}$ 211, Madrid. 
Gardner, John (2011). "What is Tort Law for? Part. 1. The Place of Corrective Justice”. Law and Philosophy, n. ${ }^{\circ}$ 30, New York.

Harlow, Carol (2004). State Liability: Tort Law and Beyond. Oxford: Oxford University Press.

Hauriou, Maurice (2002). Précis de Droit Administratif et de Droit Public. París: Éditions Dalloz.

Keren-Paz, Tsachi (2016). Derecho de daños, igualdad y justiciar distributiva. (trad.) Griselda Perrota. Madrid: Marcial Pons.

Letelier, Raúl (2012). La falta de servicio. Santiago de Chile: Abeledo Perrot Chile.

Letelier, Raúl (2012). "A modo de presentación. La falta de servicio. Aciertos y desafíos pendientes, en Raúl LeTELIER (coord.). La falta de servicio. Santiago: Abeledo Perrot Chile.

LeTELIER, Raúl (2010). "Non-contractual Liability for Breaches of EU Law. Tensión beetwen Corrective and Distributive Justice". RECON Online Working Paper. Disponible en http://www.reconproject.eu/main.php/RECON_wp_1024. pdf?fileitem $=50512007$ [Fecha de consulta: 06 de diciembre de 2021].

Nagel, Thomas (1991). Equality and Partiality. Nueva York-Oxford: Oxford University Press.

Nagel, Thomas (1979). Mortal Question. Cambridge: Cambridge University Press.

Oliver, Dawn (2013). "Accountability and the Foundations of British Democracy - The Public Interest and Public Service Principles", en Nicholas BAmforth y Peter Leyland. Accountability in the Contemporary Constitution. Oxford: Oxford University Press.

Oliver, Dawn (1991). Government in the United Kingdom: The Search for Accountability, Effectiveness and Citizenship. Milton Keynes: Open University Press.

Papayannis, Diego (2020). "Razonabilidad e incertidumbre en los estándares de diligencia”. Réplica, vol. 1, n. ${ }^{\circ}$, Santiago.

PaPayannis, Diego (2014). Comprensión y justificación de la responsabilidad extracontractual. Madrid: Marcial Pons.

Pierry, Pedro (2004). “¿Es Objetiva la Responsabilidad del Estado? Estado Actual de la Jurisprudencia”. Revista de Derecho del Consejo de Defensa del Estado, n. ${ }^{\circ} 11$.

Poblete, Gustavo (2019). "Bases conceptuales para resarcir los daños causados por la Administración Penitenciaria”, en Jonatan Valenzuela (dir.). Desafíos Globales para la Democracia. Valencia: Tirant lo Blanch.

Poblete, Gustavo (2015). "La falta de servicio ante los daños generados por desastres naturales (Corte Suprema)". Revista de Derecho (Austral), vol. 28, n. ${ }^{\circ}$ 1, Valdivia.

PONCE, Juli (2019). La lucha por el buen gobierno y el derecho a una Buena administración mediante el estándar jurídico de diligencia debida. Alcalá de Henares: Universidad Alcalá de Henares.

RAwls, John (1995). Teoría de la justicia. (trad.) María Dolores GonzÁlez. Ciudad de México: Fondo de Cultura Económica. 
Rawoski, Eric (1991). Equal Justice. New York: Oxford University Press.

RoEmer, John (1994). Egalitarian perspectives. Cambridge: Cambridge University Press.

SEn, Amartya (1992). Inequality Reexamined. Cambridge: Oxford University Press.

Stevens, Robert (2007). Torts and Rights. Oxford: Oxford University Press.

VALDIVIA, José Miguel (2020). "La responsabilidad por falta de servicio en la Administración Hospitalaria en la jurisprudencia chilena". Revista de Derecho (Concepción), vol. 87, n. ${ }^{\circ}$ 246, Concepción.

VALDivia, José Miguel (2012). "Orígenes de la noción falta de servicio", en Raúl Letelier (coord.). La falta de servicio. Santiago: Abeledo Perrot Chile.

Valdivia, José Miguel (2006). "Teoría del Órgano y Responsabilidad Pública en la Ley de Bases de la Administración del Estado". Revista de Derecho (Valdivia), vol. XIX, n. ${ }^{\circ} 2$, Valdivia.

VAN PARIJS, Philippe (1991). "Why Surfers Should be Fed: The Liberal Case for an Unconditional Basic Income". Philosophy and Public Affairs, vol. 20, n. ${ }^{\circ}$, Princeton, New Jersey.

Weinrib, Ernest (2017). La Idea del Derecho Privado. (trad.) Eze Pá́z, y revisión de Diego Papayannis. Madrid: Marcial Pons.

Weinrib, Laura y Ernest Weinrib (2001). "Constitutional Values and Private Law in Canada”, en Daniel Friedmann y Daphne Barak-Erez (eds.). Human Rights in Private Law. Oxford: Hart Publishing.

Young, Iris (1990). Justice and the Politics of Difference. New Jersey: Princeton University Press.

\section{Jurisprudencia citada}

M. D. con Fisco de Chile (2002): Corte Suprema, 15 de mayo 2002, rol n. ${ }^{\circ} 4753-$ 2001. Disponible en: https://oficinajudicialvirtual.pjud.cl/indexN.php [Fecha de consulta: 05 de diciembre de 2021].

P. S. con Fisco de Chile (2009): Corte Suprema, 30 de julio de 2009, rol n. ${ }^{\circ} 371-$ 2008. Disponible en: https://oficinajudicialvirtual.pjud.cl/indexN.php [Fecha de consulta: 05 de diciembre de 2021].

L. H. con Fisco de Chile (2012): Corte Suprema, 28 de diciembre de 2012, rol n. ${ }^{\circ}$ 2618-2012. Disponible en: https://oficinajudicialvirtual.pjud.cl/indexN. php [Fecha de consulta: 05 de diciembre de 2021].

B. U. con Servicio de Salud de la Región del Libertador Bernardo O'Higgins (2017): Corte Suprema, 09 de agosto de 2017, rol n. ${ }^{\circ}$ 10254-2017. Disponible en: https://oficinajudicialvirtual.pjud.cl/indexN.php [Fecha de consulta: 05 de diciembre de 2021].

A. F. con Servicio de Salud de Talcahuano (2018): Corte Suprema, 27 de febrero de 2018, rol n. ${ }^{\circ}$ 21599-2017. Disponible en: https://oficinajudicialvirtual.pjud. cl/indexN.php [Fecha de consulta: 05 de diciembre de 2021]. 
M. G. con Gendarmería de Chile (2020): Corte Suprema, 19 de junio de 2020, rol n. ${ }^{\circ}$ 384-2019. Disponible en: https://oficinajudicialvirtual.pjud.cl/indexN. php [Fecha de consulta: 05 de diciembre de 2021].

\author{
SigLAS Y ABREVIATURAS \\ Ley n. ${ }^{\circ} 18575$ Ley de Bases \\ n. ${ }^{\circ}$ número \\ p. página \\ pp. páginas \\ RDJ relaciones de desigualdad jurídica \\ TIE teoría de los ilícitos estatales \\ vol. volumen
}

